\title{
Trichinella spiralis ESP inhibits tumor cell growth by regulating the immune response and inducing apoptosis
}

Jing Ding ( $\nabla$ dingjing900906@163.com )

Jilin University https://orcid.org/0000-0001-9892-1657

Xiaolei Liu

Jilin University

Bin Tang

Jilin University

Xue Bai

Jilin University

Yang Wang

Jilin University

Shicun Li

Jilin University

Jian Li

Jilin University

Mingyuan Liu

Jilin University

Xuelin Wang

Jilin University

Research

Keywords: Trichinella spiralis, $\mathrm{H} 22$ cells, apoptosis, cytokines

Posted Date: March 3rd, 2021

DOl: https://doi.org/10.21203/rs.3.rs-257172/v1

License: (c) (1) This work is licensed under a Creative Commons Attribution 4.0 International License.

Read Full License 


\section{Abstract \\ Background}

Although Trichinella spiralis (T. spiralis) causes zoonotic diseases, it has a strong immunomodulatory effect and has therapeutic potential for various autoimmune diseases and cancers. Our previous study results showed that $T$. spiralis infection can inhibit the growth of liver cancer cells, but the specific mechanism has not been elucidated.

\section{Methods}

BALB/c mice injected with $\mathrm{H} 22$ cells and then infected with $T$. spiralis were used to detect tumor inhibition rate. Cell proliferation and apoptosis of $\mathrm{H} 22$ cells treated with excretory-secretory product (ESP) were measured by Cell-Counting Kit 8 (CCK-8) and Flow Cytometry (FCM). The expression of apoptosis-related genes in $\mathrm{H} 22$ cells and tumor tissues was detected by western blotting and real-time quantitative PCR (qPCR). IL-2, IFN-y and IL-4 production in the spleens were measured by qPCR and enzyme-linked immunosorbent assay(ELISA).

\section{Results}

The growth of tumors in tumor model mice infected with T. spiralis was significantly inhibited compared with those uninfected tumor model mice. ESP could inhibit $\mathrm{H} 22$ cell proliferation and induce apoptosis through the mitochondrial pathway both in vitro and in vivo. Additionally, the levels of Th1 cytokines with antitumor effects were significantly increased in the early stage of T. spiralis infection, while Th2 cytokines increased later than Th1 cytokines.

\section{Conclusions}

ESP can directly induce tumor cell apoptosis and indirectly inhibit tumor cell growth through the host immune system, which is the potential antitumor mechanism of $T$. spiralis infection.

\section{Background}

Liver cancer, including hepatocellular carcinoma (HCC) and intrahepatic cholangiocarcinoma (ICC), is one of the most common tumors worldwide. It was estimated that by the end of 2018 , liver cancer accounted for approximately 841000 new cases and 782000 deaths each year, which poses a great threat to human life and health [1]. There is also a heavy burden of liver cancer in China. Rural residents have a higher liver cancer incidence and associated mortality than their urban counterparts. The most common risk factors for liver cancer in China are chronic hepatitis B, chronic hepatitis C, aflatoxin infection, alcoholism and immune hepatitis. Unfortunately, there are deficiencies in both current surgical and 
nonsurgical treatment methods [2-6], neither surgical treatment nor nonsurgical treatment can effectively improve the outcome of liver cancer patients, so further research is necessary to find a better treatment for liver cancer.

Considerable studies indicate a negative correlation between the prevalence of some parasite infections and cancer, as these infections interfere with tumor growth. Therefore, parasite antigens seem to be promising candidates for cancer immunotherapy. Toxoplasma gondii excreted/secreted antigens play a role in the suppression of B16 tumor growth by downregulating the CD $4+C D 25+$ Treg population while upregulating the NK cell population in tumor-bearing mice. Plasmodium infection can change the tumor microenvironment and inhibit the growth of lung cancer cells [7]. In addition, Echinococcus granulosus, Taenia crassiceps and Trypanosoma cruzi were also reported to inhibit the growth of breast cancer, colon cancer, colitis-associated colorectal cancer, mammary cancer, melanoma and other cancers [8-13]. The antitumor effect of Trichinella spiralis (T. spiralis) cannot be ignored either. As a unique inflammation modulator, $T$. spiralis ensure its survival and immune dialogue with the host by releasing excretorysecretory product (ESP)[14]. T. spiralis infection was shown to inhibit B16-F10 melanoma cell growth and metastasis by reducing the production of CXCL9 and CXCL10 in a mouse model [15]. Similar inhibitory effects were also found with the myeloma cell line SP2/0 [16]. In addition, T. spiralis muscle larvae (ML) ESP can induce apoptosis in small cell lung cancer $\mathrm{H} 446$ cells through the mitochondrial pathway in vitro [17].

To study the inhibitory effect of $T$. spiralis infection on liver cancer, human hepatoma H7402 cells had been used in our experiments. Although results had shown that the T. spiralis protein A200711 has the ability to induce apoptosis in H7402 cells [18], no specific mechanism for the antitumor effect on liver cancer has been found. In this study, we evaluated the expression of relevant cytokines with quantitative real-time PCR (qPCR) and enzyme-linked immunosorbent assay (ELISA). H22 cell inhibition and apoptosis induced by ESP were assessed by using the CCK-8 method and flow cytometry (FCM). The expression of relevant genes was detected by qPCR and Western blotting to determine whether apoptosis occurs via the mitochondrial pathway. This study interprets a possible antineoplastic mechanism on the basis that $T$. spiralis infection may regulate the expression of cytokines and promote apoptosis in tumor cells.

\section{Methods}

\section{Preparation of $T$. spiralis ESP}

ICR mice infected with $T$. spiralis for thirty-five days were sacrificed, ML were collected according to the method of Beiting et al. [19], and adult worms at 6 days post infection (Ad6) were collected according to the method of Sun et al. [20]. The collected ML and Ad6 were washed multiple times with physiological saline containing $500 \mathrm{U} / \mathrm{ml}$ mycillin, transferred to RPMI 1640 medium containing $500 \mathrm{U} / \mathrm{ml}$ mycillin at a density of $5000 \mathrm{ML} / \mathrm{ml}$ and then cultured in a $5 \% \mathrm{CO}_{2}$ incubator at $37^{\circ} \mathrm{C}$ for $24 \mathrm{~h}$. Subsequently, the 
culture supernatant was collected by centrifugation, filtered using a $0.22-\mu \mathrm{m}$ filter, concentrated and stored at $-80^{\circ} \mathrm{C}$.

\section{Construction of tumor-bearing mice and grouping of experimental animals}

Cryogenic vials containing $\mathrm{H} 22$ cells were removed from liquid nitrogen and placed into warm $\left(37^{\circ} \mathrm{C}\right)$ water. After thawing, the cells were transferred into $5 \mathrm{ml}$ of complete RPMI 1640 medium (containing 10\% fetal calf serum and a $1 \%$ penicillin-streptomycin solution) and centrifuged at $1000 \mathrm{rpm}$ for $5 \mathrm{~min}$. The cells were then resuspended in complete RPMI 1640 medium for culturing. Once the cells had grown to $80 \%$ confluence in the culture dish, the cells were removed using $0.25 \%$ trypsin. After three generations, cells in the logarithmic phase were collected and subcutaneously injected into the armpit of BALB/c mice ( $1 \times 10^{5}$ cells per mouse) to construct a tumor-bearing mouse model. In this study, mice were randomly divided into four groups: the control group, tumor-bearing group, T. spiralis infection group and T. spiralis + tumor group ( $\mathrm{H} 22$ cells were injected into the mice at 7 days post infection).

\section{Calculation of the tumor inhibition rate}

Mice were sacrificed by cervical dislocation on the 27th day after injection of $\mathrm{H} 22$ cells, the tumor was harvested, and the size of the solid tumor tissue was compared between the tumor-bearing group and the T. spiralis + tumor group. Then, the tumor tissue was weighed, and the tumor inhibition rate was calculated. Tumor inhibition rate $(\%)=$ (average tumor weight of tumor-bearing group- average tumor weight of $T$. spiralis + tumor group)/average tumor weight of tumor-bearing group $\times 100 \%$.

\section{CCK-8 assay}

$\mathrm{H} 22$ cells in the logarithmic phase were seeded at 1000 cells/well in 96-well plates, and then different final concentrations of ML or Ad6 $\operatorname{ESP}(0.05,0.1,0.2$, and $0.4 \mathrm{mg} / \mathrm{ml})$ were added to the wells. After 48 hours of incubation, cell proliferation was evaluated by using CCK-8 (Med Chem Express, American). Generally, $10 \mu$ of CCK-8 solution was added to each well, and the samples were incubated for one hour before the absorbance was measured at $450 \mathrm{~nm}$. Each experiment was conducted five times.

\section{Detection of apoptosis}

In this study, flow cytometry with Annexin V and PI staining was used to detect apoptosis. Cellular samples were harvested after incubation with ML or Ad6 ESP, and the density was adjusted to $1 \times 10^{6}$ cells/ml. After double staining with Annexin $\mathrm{V}$ and PI for $15 \mathrm{~min}$ at room temperature with the Annexin $\mathrm{V}$ -

Alexa Apoptosis Detection Kit (Fcmacs, China), the samples were analyzed on a FACScan flow cytometer equipped with Cell Quest software (BD Biosciences, USA), and the results were used in apoptotic rate analyses.

\section{Western blotting}


$\mathrm{H} 22$ cells incubated with ML or Ad6 ESP for $48 \mathrm{~h}$ and mouse spleen tissue collected at different time points $(14,21,28$, and 35 d) were treated with RIPA lysis buffer. A rabbit anti-mouse Bax polyclonal antibody was used at a 1:2000 dilution, a rabbit anti-mouse Bcl-2 monoclonal antibody was used at a 1:1000 dilution, and a rabbit anti-mouse Caspase 3 polyclonal antibody was used at a 1:500 dilution. A goat secondary antibody conjugated with horseradish peroxidase was used at a 1:2000 dilution. Imaging was performed using an ECL-based system. The protein expression level was normalized to the corresponding $\beta$-tubulin level in this study.

\section{qPCR}

RNA was extracted from $\mathrm{H} 22$ cells after coculturing with ESP for $48 \mathrm{~h}$ or from mouse spleen tissue collected at different time points $(7,14,21,28$, and $35 \mathrm{~d})$ in each experiment group using TRIzol and reverse transcribed using the PrimeScript RT Reagent Kit (Trans, China). The transcriptional levels of IL-2, IFN- $y$, IL-4, Bax, Bcl-2, and Caspase-3 were normalized to those of the housekeeping gene GAPDH, and fold changes were determined by relative quantification $\left(2^{\wedge}-\Delta \Delta c t\right)$. The primers used for qPCR are listed in Table 1.

Table 1

Primers used for qPCR

\begin{tabular}{|c|c|}
\hline Genes & Primer sequence $\left(5^{\prime}-3^{\prime}\right)$ \\
\hline \multirow[t]{2}{*}{ IL-2 } & Forward: ATGTACAGCATGCAGCTCGCATCCTGTGTCA \\
\hline & Reverse: AGTCAAATCCAGAACATGCCGCAGACGTCCA \\
\hline \multirow[t]{2}{*}{ IFN-y } & Forward: CTCTTCTTGGATATCTGGAGGAACTGG \\
\hline & Reverse: AATGACGCTTATGTTGTTGCTGATGG \\
\hline \multirow[t]{2}{*}{ IL-4 } & Forward: CCTGCTCTTCTTTCTCGAATGT \\
\hline & Reverse: CTCTCTGTGGTGTTCTTCGTTG \\
\hline \multirow[t]{2}{*}{ Bax } & Forward: TTGCССТСТTCTACTTTGCTAG \\
\hline & Reverse: CCATGATGGTTCTGATCAGCTC \\
\hline \multirow[t]{2}{*}{$\mathrm{Bcl}-2$} & Forward: ACCCCTGGCATCTTCTCCTTCC \\
\hline & Reverse: CTGCGAAGTCACGACGGTAGC \\
\hline \multirow[t]{2}{*}{ Caspase-3 } & Forward: GAAACTCTTCATCATTCAGGCC \\
\hline & Reverse: GCGAGTGAGAATGTGCATAAAT \\
\hline \multirow[t]{2}{*}{ GAPDH } & Forward: ATGACATCAAGAAGGTGGTGAAG \\
\hline & Reverse: TCCTTGGAGGCCATGTAGG \\
\hline
\end{tabular}




\section{ELISA}

At different time points, the splenocyte culture supernatant of each group was quantitatively analyzed using ELISA kits (R\&D Systems, Inc., USA) for pro-inflammatory (IL-2 and IFN- $y$ ) and anti-inflammatory (IL-4) cytokines.

\section{Statistical analysis}

All the data were analyzed with SPSS 20.0 software (SPSS, Inc., USA). All the data are presented as the mean $\pm S D$, and ANOVA or a two-tailed Student's t-test was used to examine the statistical significance of comparisons of the means of different groups. $P<0.05$ was accepted as statistically significant.

\section{Results}

\section{Mice infected with T. spiralis showed tumor growth inhibition}

The mice in the T. spiralis + tumor group were injected with $\mathrm{H} 22$ cells on the 7th day after infection with $T$. spiralis (Fig. 1A). The injection time was the same in the tumor-bearing group, and the mice in the two groups were sacrificed 21 days after injection. The tumors in the T. spiralis + tumor group were significantly smaller than those in the tumor-bearing group (Fig. 1B-C), and the tumor inhibition rate calculated from tumor weight was $61.06 \pm 6.67 \%$ (Table 2).

Table 2 Tumor weight of the mice in each group and the inhibition rate

\begin{tabular}{|lll|}
\hline Group & Average tumor weight $(\mathrm{g})$ & Inhibition rate (\%) \\
\hline Tumor-bearing & $2.01905 \pm 0.658164$ & \\
\hline T. spiralis + tumor & $0.79367 \pm 0.28930039$ & $61.06 \pm 6.67$ \\
\hline
\end{tabular}

Data represent the mean value \pm SD.

\section{T. spiralis ML and Ad6 ESP inhibited H22 cell proliferation}

Different concentrations of ML or Ad6 ESP were cocultured with $\mathrm{H} 22$ cells for $48 \mathrm{~h}$, and $\mathrm{H} 22$ cell proliferation was significantly inhibited in a dose-dependent manner (Fig. 2A-B). H22 cells were cocultured with $0.2 \mathrm{mg} / \mathrm{ml} \mathrm{ML}$ or Ad6 ESP for 12, 24, 36 and $48 \mathrm{~h}$, and the growth of the treated $\mathrm{H} 22$ cells was inhibited compared with that of control cells in a time-dependent manner (Fig. 2C-D).

T. spiralis ESP induced $\mathrm{H} 22$ cell apoptosis via the mitochondrial apoptosis pathway in vitro and in vivo

After coculturing $\mathrm{H} 22$ cells with ML or Ad6 ESP for $24 \mathrm{~h}$, the apoptosis rate of the $\mathrm{H} 22$ cells was detected by FCM. The apoptosis rate of the control group was $10.33 \%$. In the experimental group, ESP at a 0.2 $\mathrm{mg} / \mathrm{mL}$ concentration induced apoptosis in $\mathrm{H} 22$ cells, with apoptosis rates of $12.22 \%$ (Ad6 ESP) and 
14.34\% (ML ESP), respectively (Fig. 3A-C), which were both higher than the rate of the control group ( $P<$ 0.05 ) (Fig. 3D), indicating that $T$. spiralis ESP induce apoptosis in $\mathrm{H} 22$ cells.

To determine whether ESP induce apoptosis in $\mathrm{H} 22$ cells through the mitochondrial pathway, we tested the changes in the expression levels of mitochondria-related genes with qPCR and Western blotting in vitro and in vivo. Compared with those in the control group, the mRNA and protein expression levels of the pro-apoptotic genes Bax and caspase 3 in the experimental groups showed increases, while the mRNA and protein expression levels of the anti-apoptotic genes Bcl-2 both decreased $(P<0.05)$ (Figs. 4). The western blot results of tumor tissue apoptosis-related genes at different days $(14,21,28,35)$ after $T$. spiralis infection are also consistent with the results in vitro (Fig. 5). Thus, the mitochondrial pathway may be a means by which ESP induce apoptosis in $\mathrm{H} 22$ cells.

\section{T. spiralis infection inhibited tumor growth by regulating cytokine expression in vivo}

ELISA results showed that the IL-2 and IFN-y levels in the splenocyte culture supernatants of the $T$. spiralis group and T. spiralis + tumor group were higher than those of the control group and tumor-bearing group at 7, 14, and 21 days. The IL-4 concentration in the splenocyte supernatants of the $T$. spiralis group and T. spiralis + tumor group was high on the 14th and 21st days, and that of the tumor-bearing group gradually increased with time (Fig. 6A). The qPCR results were basically consistent with the ELISA results (Fig. 6B).

\section{Discussion}

In this study, mice were injected with $\mathrm{H} 22$ cells on the 7th day after infection with $T$. spiralis and sacrificed 21 days after injected. It was observed that the $T$. spiralis + tumor group showed significant inhibition of tumor growth compared with the tumor-bearing group, and the inhibition rate was $61.06 \pm 6.67 \%$. To further explore the mechanism by which $T$. spiralis infection inhibits tumor growth, we examined changes in cytokine expression and those in $\mathrm{H} 22$ cell proliferation inhibition and apoptosis induced by ESP.

Different parasites can exert antitumor effects through different mechanisms. Protozoans such as Toxoplasma gondii and Trypanosoma cruzi have an antitumor effect on some types of cancer cells through an antiangiogenic capacity, immune response reactivation and apoptosis induction. On the other hand, Taenia crassiceps is able to regulate the cancer-promoting inflammatory response. Echinococcus granulosus has different antitumor mechanisms, such as immune response reactivation and antiproliferative effects on transformed cells [21]. However, the antitumor mechanism of $T$. spiralis has not yet been clearly clarified. According to several studies, the antitumor mechanism of $T$. spiralis can be divided into two types: one is regulation of the host's immune response, and the other is acting directly on tumor cells through arrest of the cell cycle and apoptosis induction in tumor cells. The antitumor effect of T. spiralis on a melanoma model established by subcutaneous injection of B16-F10 cells was achieved by complex changes in the regulation of cytokine profiles, including those of CXCL9, CXCL10, and CXCL13 [15]. A crude extract of $T$. spiralis inhibited cell proliferation through arrest of the cell cycle in the G1 or S phase in the human chronic myeloid leukemia cell line K562 and the hepatoma cell line H7402 
$[18,22] . ~ T$. spiralis ML ESP can induce apoptosis in H446 cells through the mitochondrial pathway [17]. This study explained the mechanism of the antitumor effect of $T$. spiralis on $\mathrm{H} 22$ liver cancer cells from the two perspectives of regulating the expression of host cytokines and inducing apoptosis.

At present, most studies have concluded that $T$. spiralis induces a mixed Th1/Th2 response during the intestinal phase and predominance of the Th2 response during the muscle phase. In the early stage of infection, $T$. spiralis induces an increase in the levels of the Th1 cytokines IL-2 and IFN- $\gamma$, which subsequently transforms into increases in the levels of the Th2 cytokines IL-4 and IL-13 with the migration of newborn larvae and formation of cysts [23, 24]. IL-2 and IFN- $\gamma$ are two important antitumor cytokines. IL-2 can stimulate natural killer (NK) cells, natural killer T (NKT) cells and B cells, playing an important role in antitumor immunity [25]. IFN-y has strong antitumor and immunomodulatory effects and can inhibit tumor angiogenesis and tumor development [26]. The results of this experiment showed that the expression of antitumor-related cytokines such as IL-2 and IFN- $\gamma$ increased during the acute phase of $T$. spiralis infection, which might inhibit the proliferation of tumor cells in the early stage of tumor growth.

One of two classical cell apoptosis pathways is the mitochondrial apoptotic pathway, also known as the intrinsic apoptotic pathway. The apoptosis-related genes bcl-2 and bax can control the release of cyt-c and activation of caspase-3, thereby mediating cell survival or death [27]. Bax can translocate to the mitochondrial membrane after stimulation by a death signal, and then permeable pores are formed in the mitochondrial membrane, disrupting the concentrations of ions and proteins inside and outside the membrane and releasing cyt-c and other proapoptotic factors [28]. In the presence of dATP, cyt-c combines with Apaf- 1 to form an apoptotic body and recruits procaspase-9 to oligomerize [29], thereby activating caspase -3 and initiating the caspase cascade reaction [30]. Overexpression of bcl-2 can block the process of apoptosis in three ways. One is the formation of a heterodimer with bax, which inhibits the translocation and dimerization of bax, closes the permeable pores, blocks the release of cyt-c and inhibits the activation of caspase-3 to effectively inhibit cell apoptosis [31]. Second, bcl-2 binds to Apaf- 1 and inhibits its function, preventing the activation of procaspase-9 to achieve an antiapoptotic effect [32]. Third, overexpression of bcl-2 can cause the accumulation of glutathione in the nucleus, leading to changes in the redox balance in the nucleus, preventing intracellular $\mathrm{Ca}^{2+}$ outflow, inhibiting the release of cyt-c, and thereby inhibiting the activation of caspase-3 and interrupting the process of apoptosis. To date, there are few studies on the mechanism of apoptosis induction by $T$. spiralis. Some researchers have found that the expression of apoptosis-related factors in muscles increases during cyst formation [33]. Other researchers have suggested that $T$. spiralis ML ESP induce apoptosis through the outer caspase-dependent apoptotic pathway or mitochondrial pathway [34, 35]. Here, we evaluated the changes in the expression of mitochondrial apoptosis-related genes. We found that stimulating tumor cells with ML or Ad6 ESP in vitro increased the expression of the proapoptotic gene Bax and decreased the expression of the antiapoptotic gene Bcl-2, thereby regulating the increase in the caspase-3 level and ultimately leading to apoptosis. Experiment results in vivo consisted with that in vitro. Thus, T. spiralis ESP activate intrinsic mitochondrial pathways in the process of inducing apoptosis in $\mathrm{H} 22$ cells. However, 
the involved components that participate in the antitumor effect of ESP are not yet clear, although during the formation of $T$. spiralis cysts, the p53 protein, which regulates the cell cycle and induces apoptosis, is expressed, which may lead to the inhibition of tumor growth[36].

T. spiralis ESP, which are difficult to collect, comprise a complex protein mixture, and their toxic effects on the body need to be demonstrated. If ESP are to be developed into a new drug for cancer treatment, it is necessary to further explore the components that exert the antitumor effect. Fortunately, through proteomic evaluation of ESP, it has been discovered that there are antitumor-related components, but this has not been confirmed experimentally. In the future, we may select these proteins in ESP for verification and hope to develop a new candidate for cancer treatment.

\section{Conclusions}

This study provides important data showing negative relationship between $T$. spiralis infection and $\mathrm{H} 22$ cell growth. T. spiralis infection could inhibit $\mathrm{H} 22$ cell growth by inducing apoptosis in vivo and in vitro. In addition, the Th1 cytokines induced in the early stage of $T$. spiralis infection also has anti-tumor effects. Understanding the underlying anti-tumor mechanism of $T$. spiralis infection will provide new ideas for treatment of liver cancer.

\section{Abbreviations}

T. spiralis

Trichinella spiralis

ESP

excretory-secretory product

$\mathrm{HCC}$

hepatocellular carcinoma

ICC

intrahepatic cholangiocarcinoma

CXCL

chemokine (C-X-C motif) ligand

$\mathrm{ML}$

muscle larvae

qPCR

quantitative real-time PCR

ELISA

enzyme-linked immunosorbent assay

CCK-8

Cell-Counting Kit 8

FCM

flow cytometry 
Ad6

adult worms at 6 days post infection

NK

natural killer

IL

interleukin

IFN-y

interferony

Bcl-2

B-cell lymphoma-2

Bax

Bcl-2-Associated X

Caspase

cysteinyl aspartate specific proteinase

Cyt-c

cytochrome c

Apaf-1

apoptotic protease activating factor-1

\section{Declarations}

\section{Ethics approval and consent to participate}

Ethical approval was acquired from the Institutional Life Science Ethics Committee of Jilin University (No. IZ-2009-08). The experimental animals are raised and cared on the basis of the National Guidelines for Experimental Animal Welfare of the People's Republic of China (2006).

\section{Consent for publication}

Not applicable

\section{Availability of data and materials}

The datasets used or analysed during the current study are available from the corresponding author on reasonable request.

\section{Competing Interests}

The authors disclosed no conflicts of interest regarding this publication.

\section{Funding}

This work was supported by the National Key R\&D Program of China (Grant Number 2018YFC1602500) 


\section{Authors' Contributions}

Jing Ding, Xiaolei Liu and Bin Tang performed the literature review, planned the experiments and performed data interpretation. Jing Ding performed most of the experiments and wrote the manuscript. Yang Wang performed ELISA. Shicun Li and Jian Li performed western blotting. Xue Bai was involved in optimization of the experimental protocols. Mingyuan Liu and Xuelin Wang supervised the study and performed data interpretation. All the authors contributed to editing the paper.

\section{Acknowledgments}

We thank all the staff members who provided laboratory assistance.

\section{References}

1. Bray F, Ferlay J, Soerjomataram I, Siegel RL, Torre LA, Jemal A. Global cancer statistics 2018: GLOBOCAN estimates of incidence and mortality worldwide for 36 cancers in 185 countries. Cancer J Clin. 2018;68(6):394-424.

2. Tsai KY, Chen HA, Wang WY, Huang MT. Long-term and short-term surgical outcomes of laparoscopic versus open liver resection for hepatocellular carcinoma: might laparoscopic approach be better in early HCC? Surgical endoscopy. 2019;33(4):1131-9.

3. Park GC, Song GW, Moon DB, Lee SG. A review of current status of living donor liver transplantation. Hepatobiliary surgery nutrition. 2016;5(2):107-17.

4. Raza A, Sood GK. Hepatocellular carcinoma review: current treatment, and evidence-based medicine. World journal of gastroenterology. 2014;20(15):4115-27.

5. Dutta R, Mahato RI. Recent advances in hepatocellular carcinoma therapy. Pharmacol Ther. 2017;173:106-17.

6. Chew SA, Moscato S, George S, Azimi B, Danti S. Liver Cancer: Current and Future Trends Using Biomaterials. Cancers 2019, 11(12).

7. Adah D, Yang Y, Liu Q, Gadidasu K, Tao Z, Yu S, Dai L, Li X, Zhao S, Qin L, et al. Plasmodium infection inhibits the expansion and activation of MDSCs and Tregs in the tumor microenvironment in a murine Lewis lung cancer model. Cell communication signaling: CCS. 2019;17(1):32.

8. Noya V, Bay S, Festari MF, Garcia EP, Rodriguez E, Chiale C, Ganneau C, Baleux F, Astrada S, BollatiFogolin $\mathrm{M}$, et al. Mucin-like peptides from Echinococcus granulosus induce antitumor activity. Int $\mathrm{J}$ Oncol. 2013;43(3):775-84.

9. Berriel E, Russo S, Monin L, Festari MF, Berois N, Fernandez G, Freire T, Osinaga E. Antitumor activity of human hydatid cyst fluid in a murine model of colon cancer. TheScientificWorldJournal. 2013;2013:230176.

10. Ubillos L, Freire T, Berriel E, Chiribao ML, Chiale C, Festari MF, Medeiros A, Mazal D, Rondan M, BollatiFogolin $\mathrm{M}$, et al. Trypanosoma cruzi extracts elicit protective immune response against chemically induced colon and mammary cancers. International journal of cancer. 2016;138(7):1719-31. 
11. Leon-Cabrera S, Callejas BE, Ledesma-Soto Y, Coronel J, Perez-Plasencia C, Gutierrez-Cirlos EB, AvilaMoreno F, Rodriguez-Sosa M, Hernandez-Pando R, Marquina-Castillo B, et al. Extraintestinal helminth infection reduces the development of colitis-associated tumorigenesis. Int J Biol Sci. 2014;10(9):948-56.

12. Lopez NC, Valck C, Ramirez G, Rodriguez M, Ribeiro C, Orellana J, Maldonado I, Albini A, Anacona D, Lemus D, et al. Antiangiogenic and antitumor effects of Trypanosoma cruzi Calreticulin. PLoS Negl Trop Dis. 2010;4(7):e730.

13. Atayde VD, Jasiulionis MG, Cortez M, Yoshida N. A recombinant protein based on Trypanosoma cruzi surface molecule gp82 induces apoptotic cell death in melanoma cells. Melanoma research. 2008;18(3):172-83.

14. Ding J, Liu X, Bai X, Wang Y, Li J, Wang C, Li S, Liu M, Wang X. Trichinella spiralis: inflammation modulator. Journal of helminthology. 2020;94:e193.

15. Kang YJ, Jo JO, Cho MK, Yu HS, Leem SH, Song KS, Ock MS, Cha HJ. Trichinella spiralis infection reduces tumor growth and metastasis of B16-F10 melanoma cells. Veterinary parasitology. 2013;196(1-2):106-13.

16. Gong P, Zhang J, Cao L, Nan Z, Li J, Yang J, Fang H, Jiao H, Jiang T, Su L, et al. Identification and characterization of myeloma-associated antigens in Trichinella spiralis. Experimental parasitology. 2011;127(4):784-8.

17. Luo J, Yu L, Xie G, Li D, Su M, Zhao X, Du L. Study on the mitochondrial apoptosis pathways of small cell lung cancer $\mathrm{H} 446$ cells induced by Trichinella spiralis muscle larvae ESPs. Parasitology. 2017;144(6):793-800.

18. Wang XL, Liu MY, Sun SM, Liu XL, Yu L, Wang XR, Chu LX, Rosenthal B, Shi HN, Boireau P, et al. An anti-tumor protein produced by Trichinella spiralis induces apoptosis in human hepatoma $\mathrm{H} 7402$ cells. Veterinary parasitology. 2013;194(2-4):186-8.

19. Beiting DP, Bliss SK, Schlafer DH, Roberts VL, Appleton JA. Interleukin-10 limits local and body cavity inflammation during infection with muscle-stage Trichinella spiralis. Infect Immun. 2004;72(6):3129-37.

20. Sun GG, Wang ZQ, Liu CY, Jiang P, Liu RD, Wen H, Qi X, Wang L, Cui J. Early serodiagnosis of trichinellosis by ELISA using excretory-secretory antigens of Trichinella spiralis adult worms. Parasite Vector 2015, 8.

21. Callejas BE, Martinez-Saucedo D, Terrazas LI. Parasites as negative regulators of cancer. Bioscience reports 2018, 38.

22. Wang XL, Fu BQ, Yang SJ, Wu XP, Cui GZ, Liu MF, Zhao Y, Yu YL, Liu XY, Deng HK, et al. Trichinella spiralis-A potential anti-tumor agent. Veterinary parasitology. 2009;159(3-4):249-52.

23. Ding J, Bai X, Wang X, Shi H, Cai X, Luo X, Liu M, Liu X. Immune Cell Responses and Cytokine Profile in Intestines of Mice Infected with Trichinella spiralis. Frontiers in microbiology. 2017;8:2069.

24. Ilic N, Gruden-Movsesijan A, Sofronic-Milosavljevic L. Trichinella spiralis: shaping the immune response. Immunol Res. 2012;52(1-2):111-9. 
25. Sim GC, Radvanyi L. The IL-2 cytokine family in cancer immunotherapy. Cytokine Growth Factor Rev. 2014;25(4):377-90.

26. Beatty GL, Paterson Y. Regulation of tumor growth by IFN-gamma in cancer immunotherapy. Immunol Res. 2001;24(2):201-10.

27. Scorrano L, Korsmeyer SJ. Mechanisms of cytochrome c release by proapoptotic BCL-2 family members. Biochem Bioph Res Co. 2003;304(3):437-44.

28. Ricci JE, Munoz-Pinedo C, Fitzgerald P, Bailly-Maitre B, Perkins GA, Yadava N, Scheffler IE, Ellisman $\mathrm{MH}$, Green DR. Disruption of mitochondrial function during apoptosis is mediated by caspase cleavage of the p75 subunit of complex I of the electron transport chain. Cell. 2004;117(6):773-86.

29. Daugas E, Susin SA, Zamzami N, Ferri KF, Irinopoulou T, Larochette N, Prevost MC, Leber B, Andrews $D$, Penninger $\mathrm{J}$, et al. Mitochondrio-nuclear translocation of AIF in apoptosis and necrosis. FASEB journal: official publication of the Federation of American Societies for Experimental Biology. 2000;14(5):729-39.

30. Hastak K, Gupta S, Ahmad N, Agarwal MK, Agarwal ML, Mukhtar H. Role of p53 and NF-kappaB in epigallocatechin-3-gallate-induced apoptosis of LNCaP cells. Oncogene. 2003;22(31):4851-9.

31. Guo J, Zhang K, Ji Y, Jiang X, Zuo S. Effects of ethyl pyruvate on myocardial apoptosis and expression of Bcl-2 and Bax proteins after ischemia-reperfusion in rats. 2008, 28(3):281-283.

32. Kawatani M, Imoto M. Deletion of the BH1 Domain of Bcl-2 Accelerates Apoptosis by Acting in a Dominant Negative Fashion. J Biol Chem. 2003;278(22):19732-42.

33. Babal P, Milcheva R, Petkova S, Janega P, Hurnikova Z. Apoptosis as the adaptation mechanism in survival of Trichinella spiralis in the host. Parasitol Res. 2011;109(4):997-1002.

34. Vasilev S, Ilic N, Gruden-Movsesijan A, Vasilijic S, Bosic M, Sofronic-Milosavljevic L. Necrosis and apoptosis in Trichinella spiralis-mediated tumour reduction. Cent Eur J Immunol. 2015;40(1):42-53.

35. Luo JM, Yu L, Xie GC, Li D, Su M, Zhao XR, Du LY. Study on the mitochondrial apoptosis pathways of small cell lung cancer $\mathrm{H} 446$ cells induced by Trichinella spiralis muscle larvae ESPs. Parasitology. 2017;144(6):793-800.

36. Boonmars T, Wu Z, Nagano I, Takahashi Y. What is the role of p53 during the cyst formation of Trichinella spiralis? A comparable study between knockout mice and wild type mice. Parasitology. 2005;131:705-12.

\section{Figures}




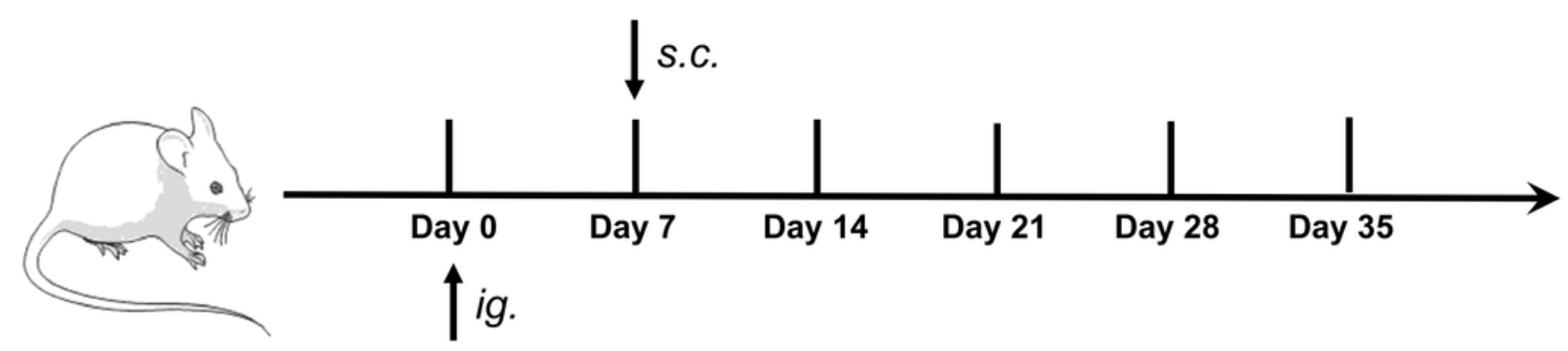

\section{T. spiralis infection}

B

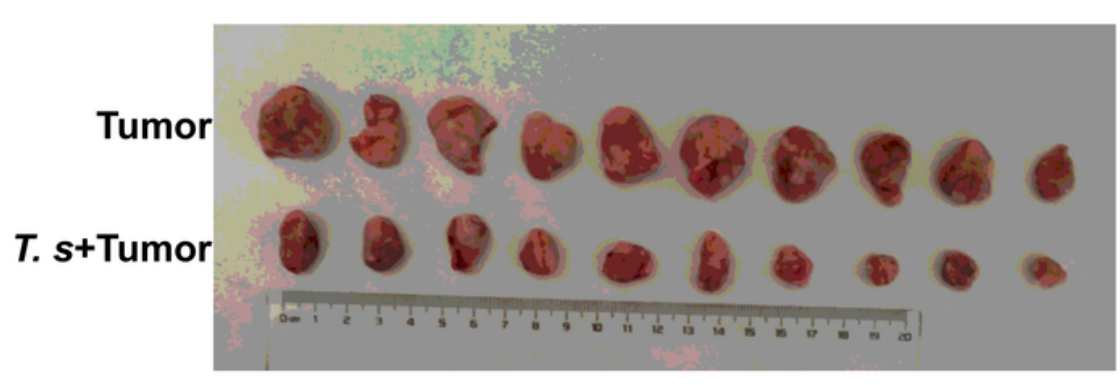

C

\section{Figure 1}

Tumor growth inhibition by T. spiralis infection. (A) Schematic diagram of infection method in T. spiralis+tumor group. Subcutaneous injection of $\mathrm{H} 22$ cells (1×105 per mouse) in the armpit of mice 7 days after intragastric infection with T. spiralis ML (300 per mouse). (B) Tumors harvested from mice in the tumor-bearing group and T. spiralis+tumor group at 35 days. (C) Analysis of differences in tumor weight of tumor-bearing group and T. spiralis+tumor group. ${ }^{\star \star \star} P<0.001(n=10)$. 
A

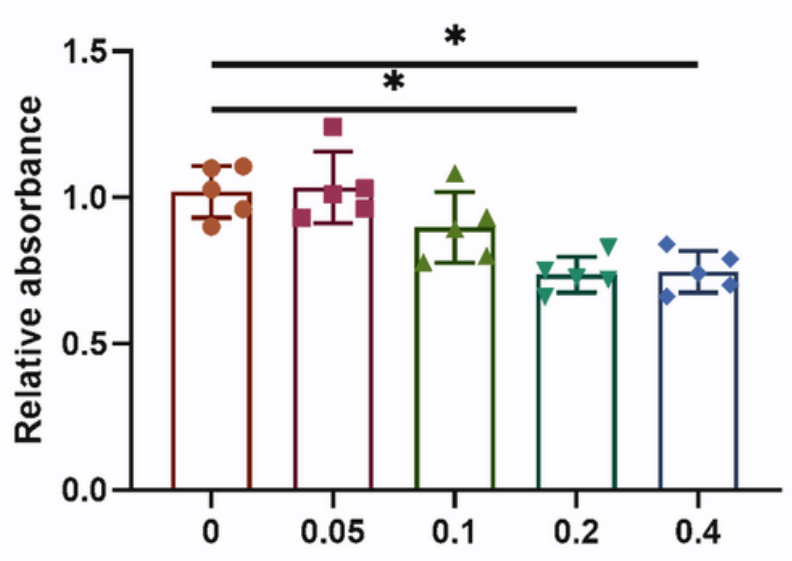

Concentration of Ad6 ESP $(\mathrm{mg} / \mathrm{mL})$

C

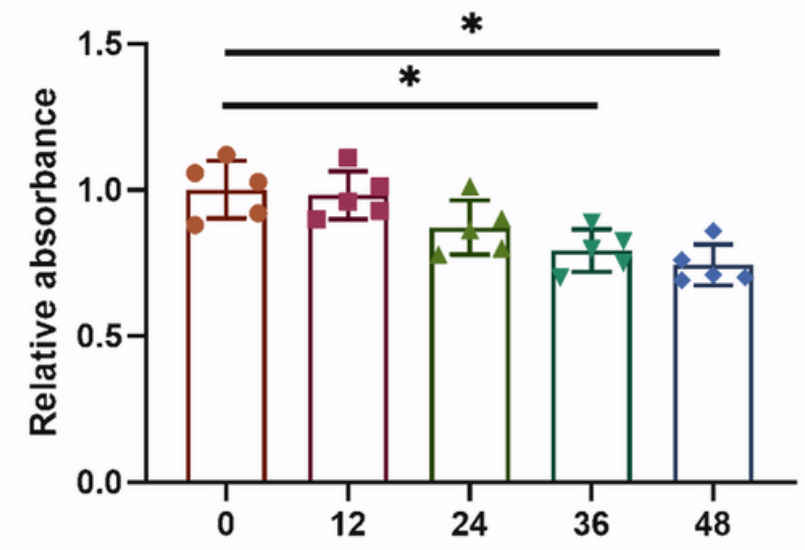

Ad6 ESP incubation time (h)
B

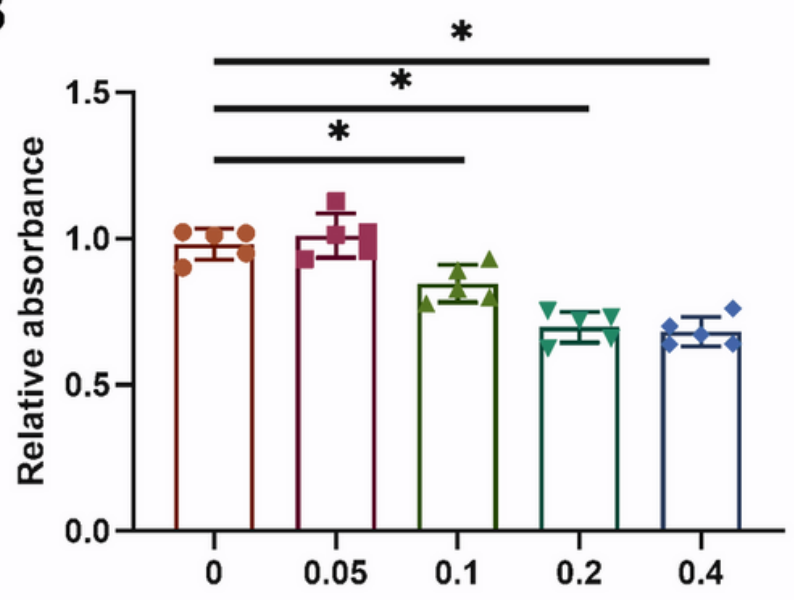

Concentration of ML ESP $(\mathrm{mg} / \mathrm{mL})$

D

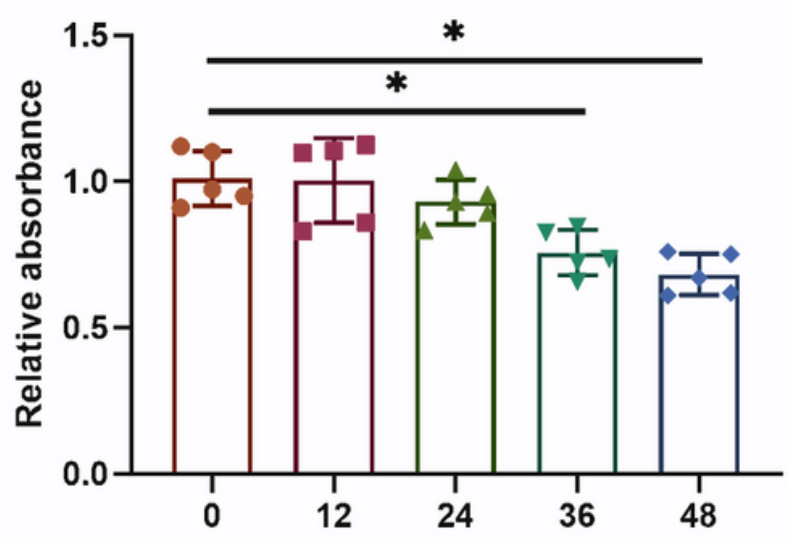

ML ESP incubation time (h)

Figure 2

Effect of ESP on $\mathrm{H} 22$ cell proliferation. (A) Different concentrations of Ad6 ESP $(0.05,0.1,0.2$ and 0.4 $\mathrm{mg} / \mathrm{mL})$ cocultured with $\mathrm{H} 22$ cells for $24 \mathrm{~h}$ in vitro. (B) Different concentrations of $\mathrm{ML}$ ESP $(0.05,0.1,0.2$ and $0.4 \mathrm{mg} / \mathrm{mL})$ cocultured with $\mathrm{H} 22$ cells for $24 \mathrm{~h}$ in vitro. (C) Ad6 ESP $(0.2 \mathrm{mg} / \mathrm{mL})$ cocultured with $\mathrm{H} 22$ cells for $12,24,36$ and $48 \mathrm{~h}$ in vitro. (D) ML ESP $(0.2 \mathrm{mg} / \mathrm{mL})$ cocultured with $\mathrm{H} 22$ cells for $12,24,36$ and $48 \mathrm{~h}$ in vitro. The values shown are the mean \pm S.D. ${ }^{*} P<0.05$ relative to negative controls $(n=5)$. 

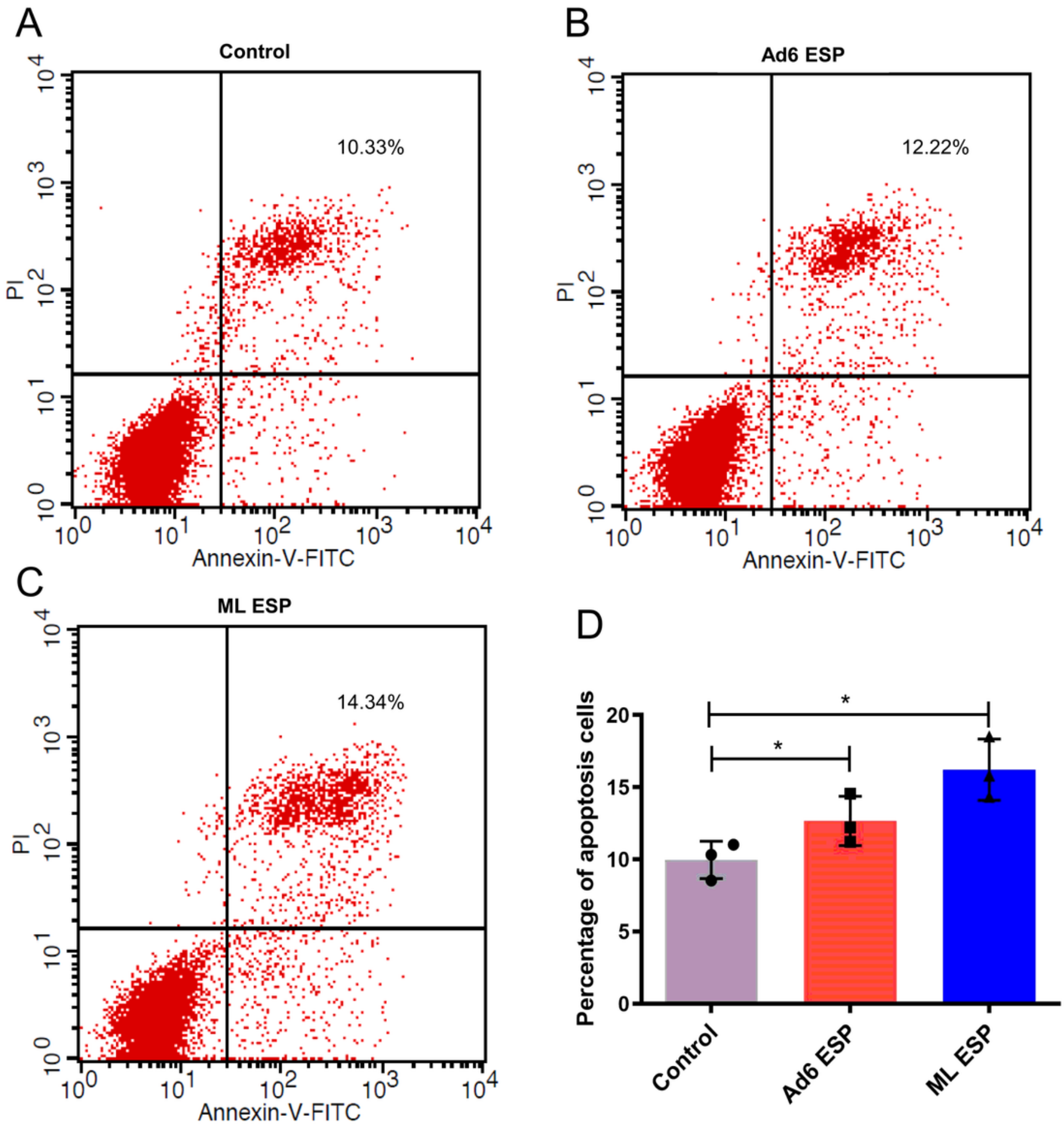

Figure 3

Effect of ESP on H22 cell apoptosis. (A) Negative control, (B) $0.2 \mathrm{mg} / \mathrm{mL}$ Ad6 ESP cocultured with H22 cells for $24 \mathrm{~h}$, and (C) $0.2 \mathrm{mg} / \mathrm{mL}$ ML ESP cocultured with $\mathrm{H} 22$ cells for $24 \mathrm{~h}$. The cells were collected, stained with Annexin V/PI and then analyzed by FCM. (D) Data analysis; $* \mathrm{P}<0.05$ relative to the negative control $(n=3)$. 
A

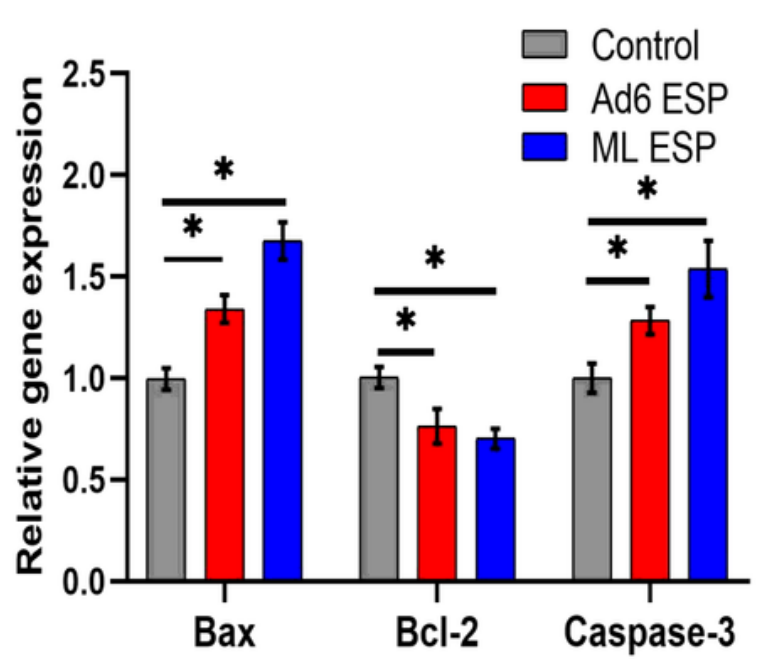

B

Bax

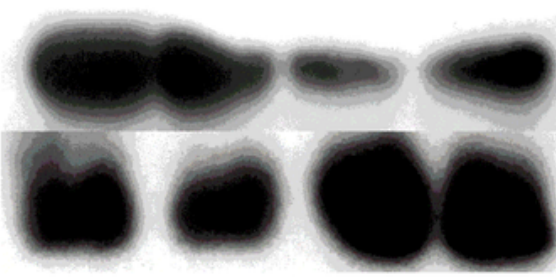

Caspase-3

$\beta$-tubulin
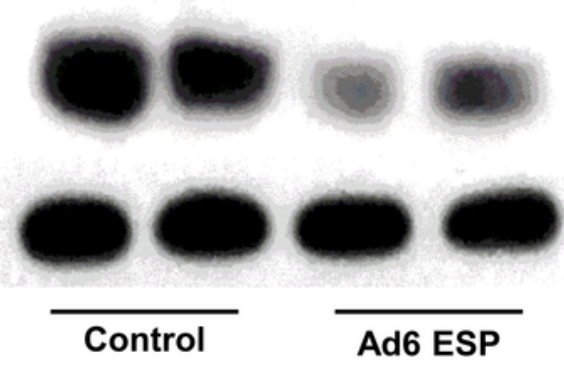

C

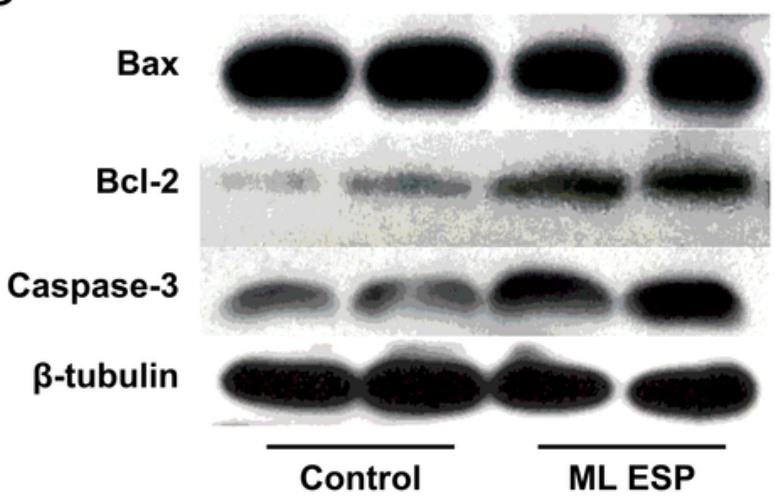

Figure 4

Effects of ESP on the expression of apoptosis-related genes in H22 cells. (A) mRNA expression of Bax, Bcl-2, and Caspase-3 in H22 cells. H22 cells were treated with Ad6 or ML ESP $(0.2 \mathrm{mg} / \mathrm{mL})$ for $24 \mathrm{~h}$. The expression of each gene was measured by qPCR using the GAPDH gene as a reference for normalization of gene expression. The values shown are the mean \pm S.D. $(n=3) .{ }^{*} P<0.05$ compared with the control. (B) Ad6 ESP $(0.2 \mathrm{mg} / \mathrm{mL})$ or (C) ML ESP $(0.2 \mathrm{mg} / \mathrm{mL})$ were cocultured with $\mathrm{H} 22$ cells for $24 \mathrm{~h}$. Then, total 
protein was obtained from the $\mathrm{H} 22$ cells and expression of Bax, Bcl-2, Caspase-3 was detected by Western blotting using the $\beta$-tubulin gene as a reference for normalization of protein expression. $\mathrm{H} 22$ cells not cocultured were ESP were used as control.

A

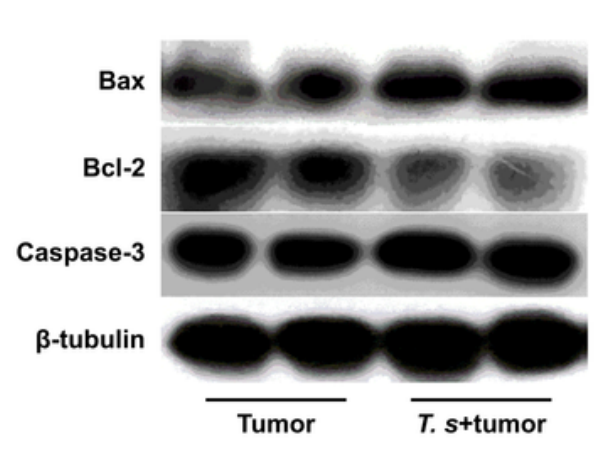

B

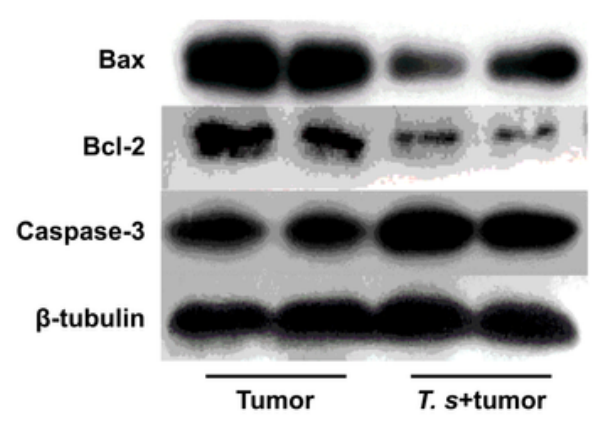

C

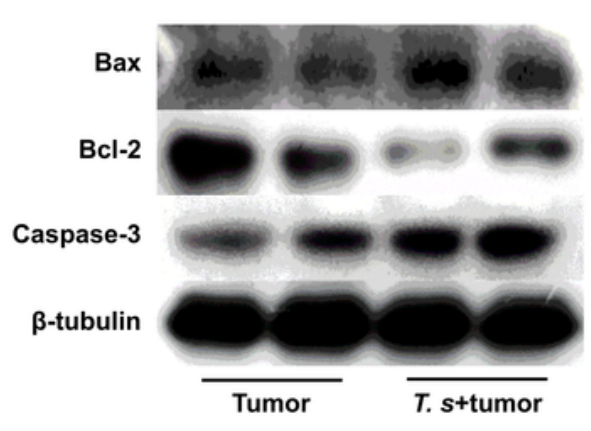

$\mathrm{D}$

$35 \mathrm{~d}$

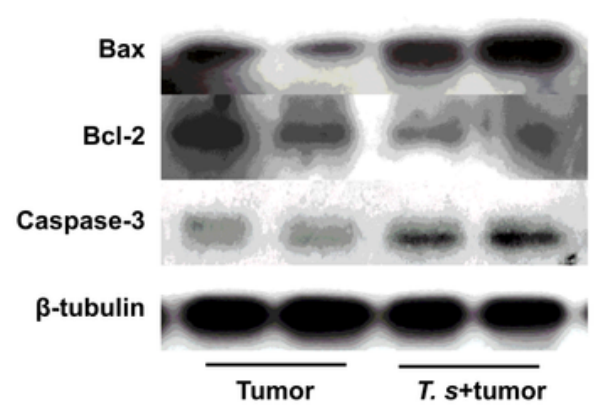

$14 \mathrm{~d}$

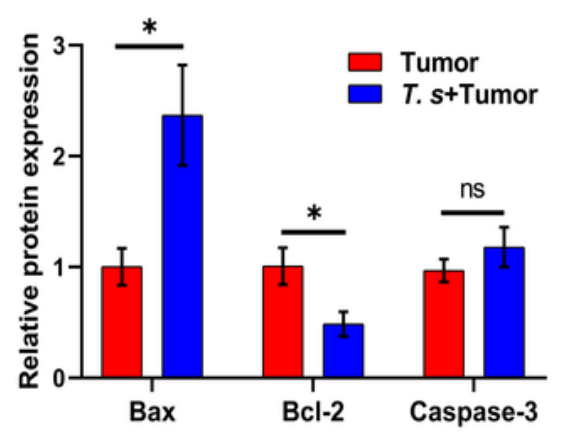

21 d

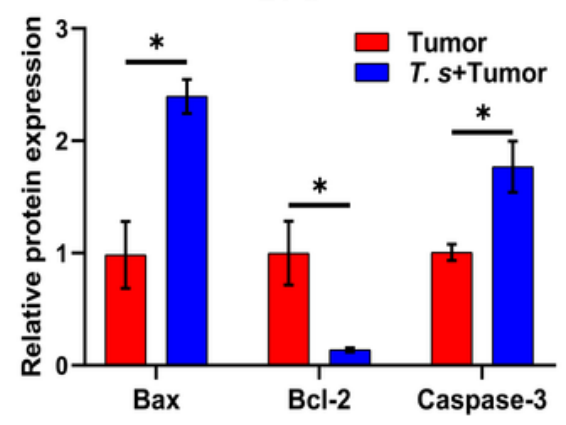

$28 d$

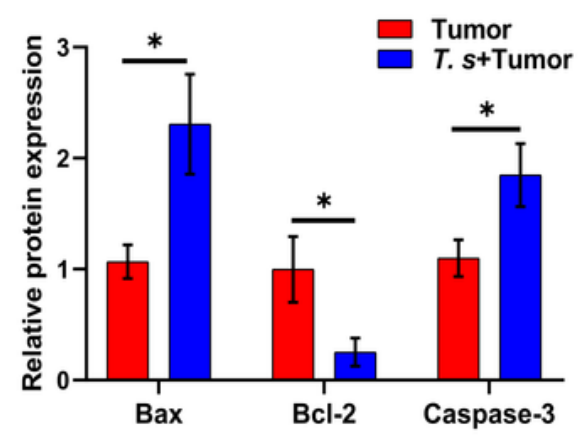

$35 \mathrm{~d}$

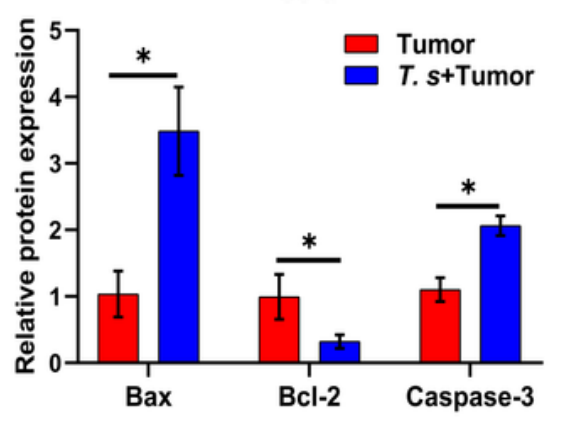

Figure 5

Expression of $\mathrm{Bax}, \mathrm{Bcl}-2$, and Caspase- 3 in tumor tissue determined by Western blotting. Tumor tissue were harvested at (A) $14 \mathrm{~d},(\mathrm{~B}) 21 \mathrm{~d},(\mathrm{C}) 28 \mathrm{~d}$ and (D) $35 \mathrm{~d}$ from Tumor group (control) and T. s+Tumor 
group. Then, total protein was obtained from the tumor tissues and detected by Western blotting using the $\beta$-tubulin gene as a reference for normalization of protein expression. The gray values shown are the mean \pm S.D. $(n=3)$. ${ }^{*} P<0.05$ compared with the control.

A
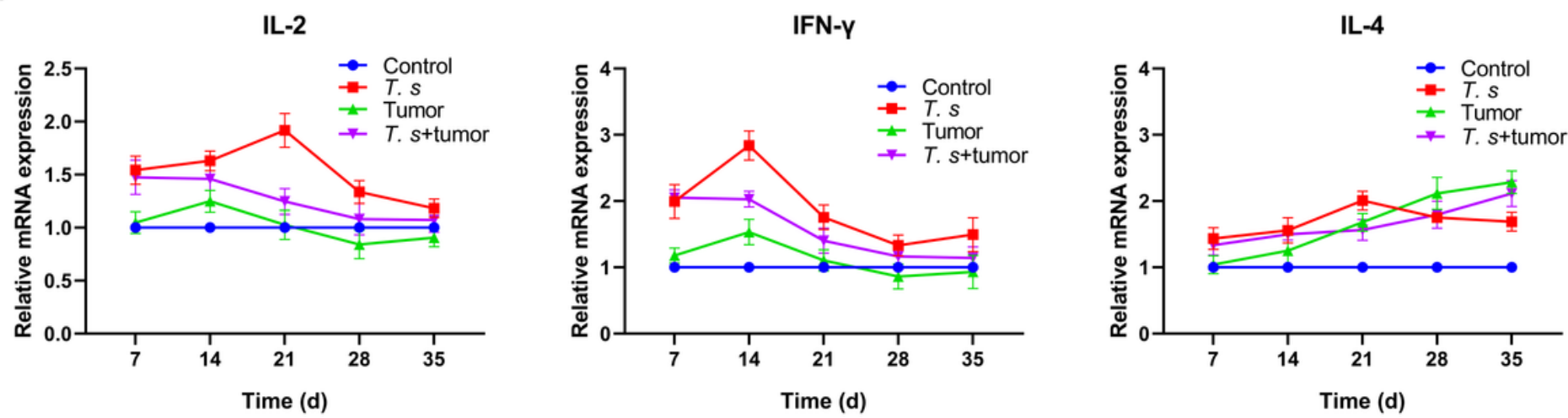

B

IL-2

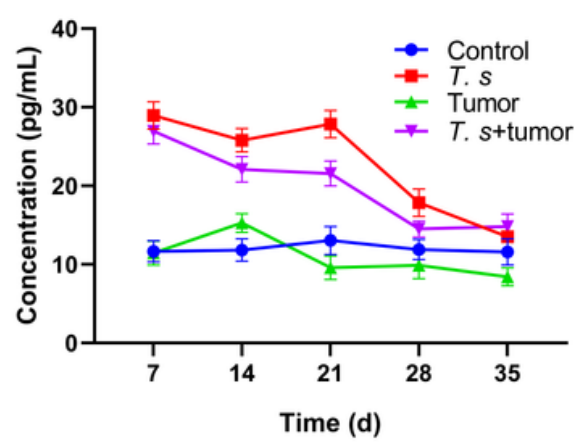

IFN-Y

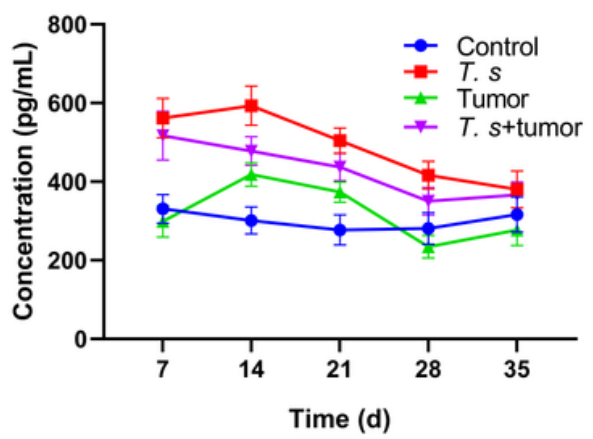

IL-4

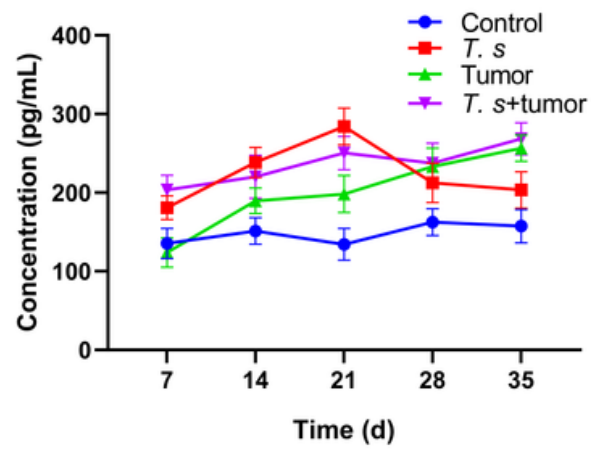

Figure 6

Effect of T. spiralis infection on the expression of cytokines in the spleen. (A) mRNA levels of IL-2, IFN- $\gamma$ and IL-4 in the spleen. Total RNA was extracted from the spleen, and cytokines mRNA were assayed by qPCR using the GAPDH gene as a reference for normalization of gene expression. (B) Protein expression of IL-2, IFN- $y$ and IL-4 in the spleen. Total protein was obtained from the spleen and assessed by ELISA. The values shown are the mean \pm S.D. $(n=3)$.

\section{Supplementary Files}

This is a list of supplementary files associated with this preprint. Click to download.

- renamed2b4af.tif 